Article

\title{
Degradation and Detoxification of Aflatoxin B1 by Tea-Derived Aspergillus niger RAF106
}

\author{
Qian'an Fang ${ }^{1}$, Minru Du ${ }^{1}$, Jianwen Chen ${ }^{1}$, Tong Liu ${ }^{1}$, Yong Zheng ${ }^{1}$, Zhenlin Liao ${ }^{1,2}$, \\ Qingping Zhong ${ }^{1,2}$, Li Wang ${ }^{1,2}$, Xiang Fang ${ }^{1,2, *}$ and Jie Wang ${ }^{1,2,3, *}$ \\ 1 Guangdong Provincial Key Laboratory of Food Quality and Safety, College of Food Science, \\ South China Agricultural University, Guangzhou 510642, China; twingofang@163.com (Q.F.); \\ duminru2016@163.com (M.D.); cjw905368952@126.com (J.C.); Pluto0523@126.com (T.L.); \\ zhengyong@qianweish.com (Y.Z.); larryliao@scau.edu.cn (Z.L.); zhongqp@scau.edu.cn (Q.Z.); \\ wangli_scau@scau.edu.cn (L.W.) \\ 2 Lingnan Guangdong Laboratory of Modern Agriculture, Guangzhou 510642, China \\ 3 Guangdong Open Laboratory of Applied Microbiology, Guangdong Provincial Key Laboratory of Microbial \\ Culture Collection and Application, State Key Laboratory of Applied Microbiology Southern China, \\ Guangdong Institute of Microbiology, Guangdong Academy of Sciences, Guangzhou 510070, China \\ * Correspondence: fxiang@scau.edu.cn (X.F.); jiewang@scau.edu.cn (J.W.)
}

Received: 25 November 2020; Accepted: 2 December 2020; Published: 6 December 2020

check for updates

\begin{abstract}
Microbial degradation is an effective and attractive method for eliminating aflatoxin B1 (AFB1), which is severely toxic to humans and animals. In this study, Aspergillus niger RAF106 could effectively degrade AFB1 when cultivated in Sabouraud dextrose broth (SDB) with contents of AFB1 ranging from 0.1 to $4 \mu \mathrm{g} / \mathrm{mL}$. Treatment with yeast extract as a nitrogen source stimulated the degradation, but treatment with $\mathrm{NaNO}_{3}$ and $\mathrm{NaNO}_{2}$ as nitrogen sources and lactose and sucrose as carbon sources suppressed the degradation. Moreover, A. niger RAF106 still degraded AFB1 at initial $\mathrm{pH}$ values that ranged from 4 to 10 and at cultivation temperatures that ranged from 25 to $45^{\circ} \mathrm{C}$. In addition, intracellular enzymes or proteins with excellent thermotolerance were verified as being able to degrade AFB1 into metabolites with low or no mutagenicity. Furthermore, genomic sequence analysis indicated that the fungus was considered to be safe owing to the absence of virulence genes and the gene clusters for the synthesis of mycotoxins. These results indicate that A. niger RAF106 and its intracellular enzymes or proteins have a promising potential to be applied commercially in the processing and industry of food and feed to detoxify AFB1.
\end{abstract}

Keywords: aflatoxin B1; Aspergillus niger; intracellular extracts; Ames test; genome sequencing

Key Contribution: Tea-derived Aspergillus niger RAF106, a safe and potentially useful fungus, could effectively detoxify AFB1 to compounds with low or no mutagenicity in environments with $\mathrm{pH}$ values from 4 to 10 and temperatures from 25 to $45^{\circ} \mathrm{C}$, and its AFB1-degrading proteins or enzymes in the intracellular extracts possess excellent thermostability. This is the first study to demonstrate $80 \%$ degradation of AFB1 over $24 \mathrm{~h}$ of incubation in A. niger strains and provides a potential optimal solution to eliminate AFB1 contamination from food and feed.

\section{Introduction}

Mycotoxins, such as aflatoxins, ochratoxin A, fumonisins, deoxynivalenol, and zearalenone, are toxic metabolites that are primarily produced by fungi, including Aspergillus, Penicillium, and Fusarium, and have contaminated approximately $60-80 \%$ of the food and feed around the world [1,2]. For example, the incidence and maximum level in raw cereal grains were $55 \%$ and $1642 \mu \mathrm{g} / \mathrm{kg}$ for aflatoxins based on the global occurrence data reported during the past 10 years [1]. 
Among them, aflatoxin B1 (AFB1), a bisfuranocoumarin derivative, is the most toxic contaminant and causes carcinogenic, teratogenic, hepatotoxic, and immunosuppressive effects in humans and many types of animals, including poultry, trout, cattle, and rats, with different incidences across species, gender, and age [3-5]. Therefore, it poses a serious threat to livestock productivity and human health. The key sites in AFB1 regarding its toxicity, mutagenicity, and carcinogenesis are the lactone ring in the common coumarin structure and the double bond of the terminal furan rings [6,7]. In addition, owing to its high liposolubility, AFB1 can easily enter the bloodstream and reach organs, particularly the liver, and be metabolized to aflatoxin M1 (AFM1) there. AFM1 can appear in milk, and thus dairy products, and exhibit carcinogenic and immunosuppressive effects similar to that of AFB1, even if with a less potent effect $[8,9]$. Therefore, the contamination of AFB1 in food and feed results in enormous economic losses and public health and safety problems [10,11]. AFB1-related health problems tend to be the most severe in developing nations, and approximately 4.5 billion people are chronically exposed owing to the lack of regulation of AFB1 [12]. Considering the potential hazards to animal and human health, there is an urgent need to lower the content of AFB1 to the established permissible levels in food and feed, which vary from 0 to $50 \mu \mathrm{g} / \mathrm{kg}$ in different countries [13].

Several ways, including physical, chemical, and biological methods, have been proposed to eliminate AFB1 and prevent agricultural products from AFB1 contamination. Compared with physical and chemical methods, microbial degradation is receiving much attention owing to its advantages, such as the mild reactions, minimal loss of product qualities, eco-friendly nature, and feasible processes when applied in an industrial setting [14,15]. Over the past several decades, it has been reported that many bacteria and fungi can detoxify AFB1 to less toxic metabolites. For example, AFB1 was converted into AFB2a and AFD1 by Lactobacillus delbrueckii [16]; AFD1, AFD2, and AFD3 by Pseudomonas putida [17]; AFD1 and AFD2 by Rhodococcus erythropolis [18]; AFB1-8,9-dihydrodiol by Phanerochaete sordida YK-624 [19]; aflatoxicol by Eurotium herbariorum, Rhizopus spp., Mucor alternans, and Trichoderma viride [20]. Although these fungi and bacteria can detoxify AFB1, few strains have been developed into a commercial product for the biological prevention of aflatoxin contamination because of the narrow working temperature range, unsuitability for the processing environment, and the safety of these microorganisms [21,22]. Therefore, it is still worth exploring safe microorganisms that are suitable for food and feed processing and can degrade AFB1 to less toxic metabolites with excellent degradation efficiency over wide temperature and $\mathrm{pH}$ ranges.

Aspergillus niger, a filamentous ascomycete fungus that is generally recognized as safe (GRAS) by the U.S. Food and Drug Administration (FDA), has been widely applied in the fermentation industry and food processing, including the production of various organic acids, enzymes, and bioactive compounds, as well as the improvement of the sensory characteristics of fermented foods [23-25]. For example, in post-fermented Pu-erh tea, A. niger is one of the dominant strains and produces various enzymes that catalyze the metabolism of chemical compounds, such as converting tea polyphenols to bioactive theabrownins and producing the main flavor characteristics of Pu-erh tea [25]. Recently, A. niger ND-1 isolated from feed ingredients and A. niger FS-Z1 have been reported to be capable of degrading AFB1 [26,27]. However, the highest degradation rate of AFB1 in wild-type A. niger is $58.52 \%$ after $48 \mathrm{~h}$ of incubation, and with the exception of aflatoxicol, the metabolites from AFB1 degradation mediated by $A$. niger and their toxicity remain unknown [26-28]. Additionally, it has been reported that some $A$. niger strains produce mycotoxins, such as ochratoxin and fumonisin $[29,30]$, but it was still unknown whether the AFB1-degrading A. niger strains produce mycotoxins.

In this study, we found that $A$. niger RAF106, a catechin-transforming fungus isolated from Pu-erh tea [31], could degrade AFB1 by $88.59 \%$ after $72 \mathrm{~h}$. The initial part of this study that focused on improving the degradation rates of AFB1 examined the optimal conditions by assessing the effects of the AFB1 concentrations, nutrients, initial $\mathrm{pH}$, and temperatures on the degradation of AFB1. Second, to illuminate the characteristics of AFB1 degradation mediated by A. niger RAF106, the active ingredient to degrade AFB1 and the potential metabolites were investigated in optimal conditions. Lastly, the mutagenic potential of the degradation metabolites was also evaluated, and the genome of 
A. niger RAF106 was sequenced to assess whether the strain is a potential atoxigenic strain. These results will be helpful in developing safe and effective AFB1-degrading agents that are associated with $A$. niger RAF106, which can be commercially used in the process and manufacture of food and feed.

\section{Results}

\subsection{AFB1 Degradation by A. niger RAF106 and the Effect of AFB1 on Fungal Development}

There was no significant variation in the concentration (Tukey's honestly significant difference (HSD), $p>0.05$ ) when AFB1 was incubated in Sabouraud dextrose broth (SDB) with shaking for $72 \mathrm{~h}$ at $30{ }^{\circ} \mathrm{C}$ (data not shown). However, the chromatographic peak area of AFB1 decreased as the incubation time increased (Figure 1A) when incubated with A. niger RAF106. The percentage of AFB1 degradation was 30.99\%, 52.71\%, and $88.59 \%$ at the incubation times of 24, 48, and $72 \mathrm{~h}$, respectively (Figure 1B), suggesting that $A$. niger RAF106 could degrade AFB1 in a time-dependent manner. Moreover, compared with those of the cultures with no AFB1, the biomass of $A$. niger RAF106 at 24 and $48 \mathrm{~h}$ was slightly reduced by 12.78-16.94\% (Tukey's HSD, $p<0.05$ ), but the biomass at $72 \mathrm{~h}$ showed no significant changes (Figure 1C), suggesting that AFB1 did not inhibit the hyphal growth of $A$. niger RAF106 over 72 h of incubation. However, when incubated with $A$. niger RAF106 on Sabouraud dextrose agar (SDA) plates, AFB1 caused some defects in the production of the black conidia, although no obvious change was observed in the diameters of the fungal colonies (Figure 1D). As shown in Figure 1D, the presence of AFB1 caused a 33.22-45.24\% decrease in the conidial yields of A. niger RAF106 over $72 \mathrm{~h}$ of cultivation (Tukey's HSD, $p<0.05$ ). These results demonstrated that the hyphal growth of $A$. niger RAF106 was almost unaffected during the degradation of AFB1, although a reduction in conidiation was observed.
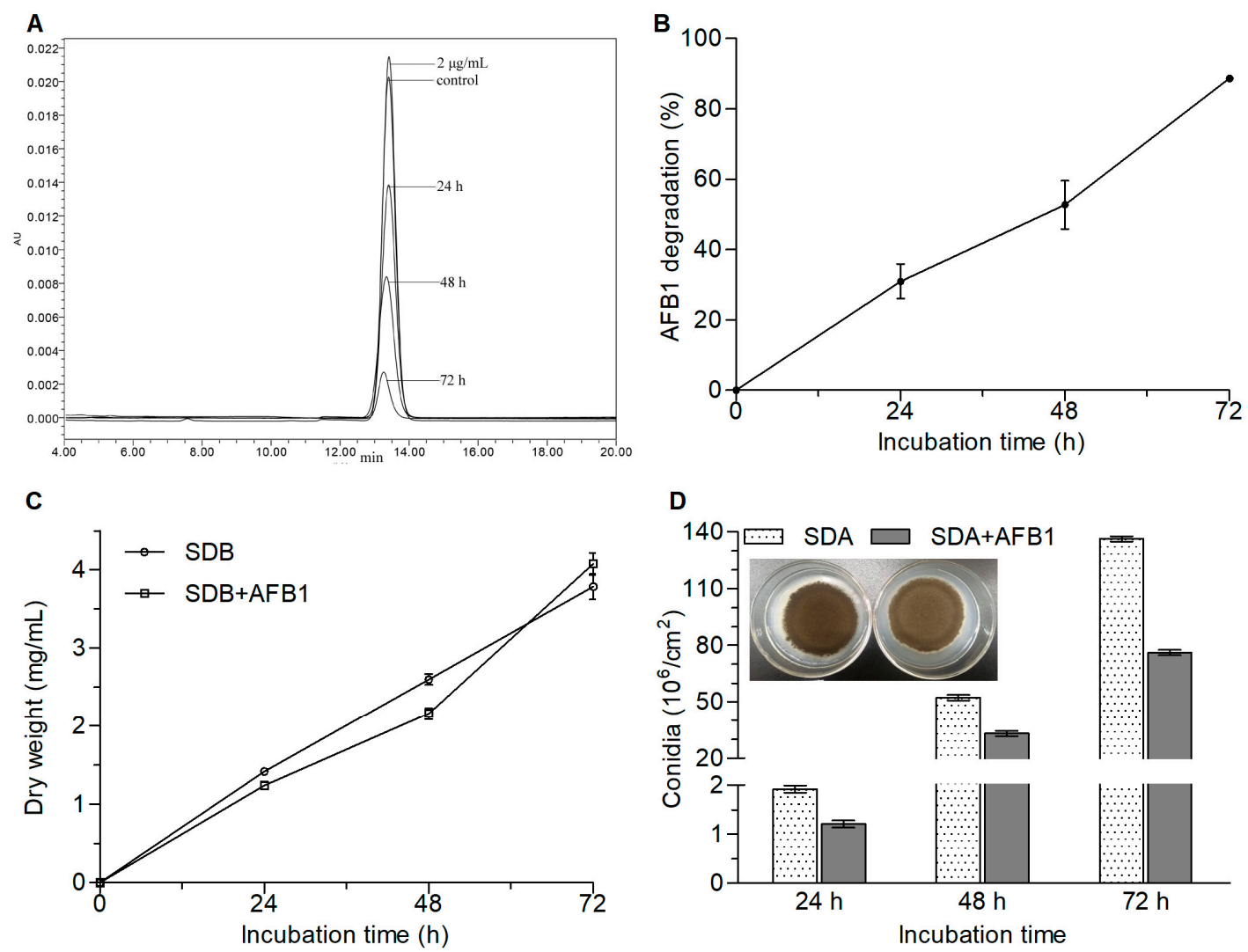

Figure 1. Changes in the residual AFB1 and fungal development when A. niger RAF106 was co-cultivated with $2 \mu \mathrm{g} / \mathrm{mL}$ AFB1 for $72 \mathrm{~h}$ at $30{ }^{\circ} \mathrm{C}$. (A) High-performance liquid chromatography (HPLC) chromatogram of $2 \mu \mathrm{g} / \mathrm{mL}$ AFB1 and extracted AFB1 from the AFB1-degrading cultures 
mediated by A. niger RAF106 for different incubation times. The concentration of AFB1 incubated in Sabouraud dextrose broth (SDB) with shaking was used as control. (B) The percentages of AFB1 degradation for different incubation times. (C) Dry weight of $A$. niger RAF106 cultivated in SDB and SDB with AFB1 for different incubation times. (D) The colony and conidial yields of $A$. niger RAR106 grown on the Sabouraud dextrose agar (SDA) and SDA supplemented with AFB1 for different incubation times.

\subsection{Effects of the Fermentation Conditions on AFB1 Degradation}

To accelerate the degradation of AFB1, the effects of the AFB1 concentrations, nutrients, initial $\mathrm{pH}$ values, and temperatures on the degradation of the compound were investigated for $A$. niger RAF106. In terms of the AFB1 concentrations, we found that the degradation rate decreased with an increase in the initial concentrations of AFB1 (Figure 2A). For example, in a comparison of the degradation activity at $24 \mathrm{~h}$, compared with the estimate of $72.50 \%$ in the group with $0.1 \mu \mathrm{g} / \mathrm{mL}$ AFB1, the percentage of AFB1 degradation decreased by $57.26 \%$ in the group with $2 \mu \mathrm{g} / \mathrm{mL}$ AFB1 (Student's $t_{4}=16.70, p=0.0001$ ) and $71.45 \%$ in the group with $4 \mu \mathrm{g} / \mathrm{mL}$ AFB1 (Student's $t_{4}=31.53, p=0.0001$ ). Considering the limit of quantitation (LOQ) and the maximum level in raw cereal grains, $2 \mu \mathrm{g} / \mathrm{mL}$ AFB1 was chosen to conduct the following studies.

With respect to the effects of nutrients on the AFB1 degradation, it was found that the use of yeast extract as the nitrogen source accelerated the degradation of AFB1 by $12.68-158.90 \%$, but $\mathrm{NaNO}_{3}$ and $\mathrm{NaNO}_{2}$ slowed the degradation by $37.67-82.15 \%$ compared with that in SDB with tryptone as the nitrogen source (native SDB) over $72 \mathrm{~h}$ of incubation (Figure 2B). When A. niger RAF106 was cultivated with AFB1 in modified SDB with yeast extract, the percentage of AFB1 degradation reached $80 \%$ at $24 \mathrm{~h}$ of fermentation (Figure 2B). In terms of carbon sources, both sucrose and lactose inhibited the degradation of AFB1 by $35.60-54.48 \%$ compared with that in SDB with glucose as the carbon source over $72 \mathrm{~h}$ of cultivation (Figure 2B).

With regard to the influence of the initial $\mathrm{pH}$ on the degradation of AFB1 in A. niger RAF106, we found that the degradation mediated by $A$. niger RAF106 was unaffected by the initial $\mathrm{pH}$ values. For example, there was no noticeable difference on the degradation of AFB1 between different initial $\mathrm{pH}$ values from 4 to 8 after $48 \mathrm{~h}\left(F_{4,14}=0.49, p=0.74\right.$; Figure $\left.2 \mathrm{C}\right)$. When the initial $\mathrm{pH}$ value reached 10 , the content of AFB1 was degraded to less than the LOQ value in the control group (data not shown).

Additionally, the degradation of AFB1 was affected by the fermentation temperature (Figure 2D). Compared with those at $30{ }^{\circ} \mathrm{C}$, the percentages of AFB1 degradation decreased by $18.75-48.14 \%$ at $25^{\circ} \mathrm{C}$ and by more than $90 \%$ at $45^{\circ} \mathrm{C}$ over $72 \mathrm{~h}$ of incubation (Figure 2D). However, the percentages of AFB1 degradation at $37^{\circ} \mathrm{C}$ and $40^{\circ} \mathrm{C}$ were nearly identical to those at $30^{\circ} \mathrm{C}$ when the incubation time lasted $48 \mathrm{~h}$ and $72 \mathrm{~h}$, even though the percentages were inhibited by $30.81-36.29 \%$ after the first $24 \mathrm{~h}$ of incubation (Figure 2D).

Moreover, to assess whether the changes in the degradation of AFB1 caused by different fermentation conditions were dependent on fungal growth, the effects of nutrients, initial $\mathrm{pH}$ values, and temperatures on fungal growth were investigated in A. niger RAF106. As shown in Figure 2E, the presence of yeast extract or lactose promoted the fungal growth by $113.21 \%$ and $23.93 \%$, respectively, but the presence of $\mathrm{NaNO}_{3}$ or $\mathrm{NaNO}_{2}$ inhibited the fungal growth by $87.60 \%$ and $97.89 \%$, respectively, compared with the growth in the native SDB. However, the fungal growth in the presence of sucrose was similar to that in the native SDB (Student's $t_{4}=0.53, p=0.63$ ). Among the different initial $\mathrm{pH}$ values that ranged from 4 to 10 , there were no obvious changes in fungal growth $\left(F_{5,17}=1.11, p=0.40\right.$; Figure 2F). In terms of temperature, compared with those at $30^{\circ} \mathrm{C}$, the fungal biomass was inhibited by $86.85-96.79 \%$ at $45^{\circ} \mathrm{C}$ over $72 \mathrm{~h}$ of incubation (Figure $2 \mathrm{G}$ ). However, the amounts of fungal biomass at $25^{\circ} \mathrm{C}, 37^{\circ} \mathrm{C}$, and $40^{\circ} \mathrm{C}$ were nearly identical to that at $30^{\circ} \mathrm{C}$ when the incubation time lasted $48 \mathrm{~h}$ and $72 \mathrm{~h}$, even though the biomass was inhibited by $30.26-46.16 \%$ after the first $24 \mathrm{~h}$ of incubation (Figure 2G). A comparison of the changes in the degradation of AFB1 and fungal biomass caused by fermentation conditions suggested that there was a correlation between AFB1 degradation and fungal growth, but the AFB1 degradation did not completely depend on fungal growth in A. niger RAF106. 

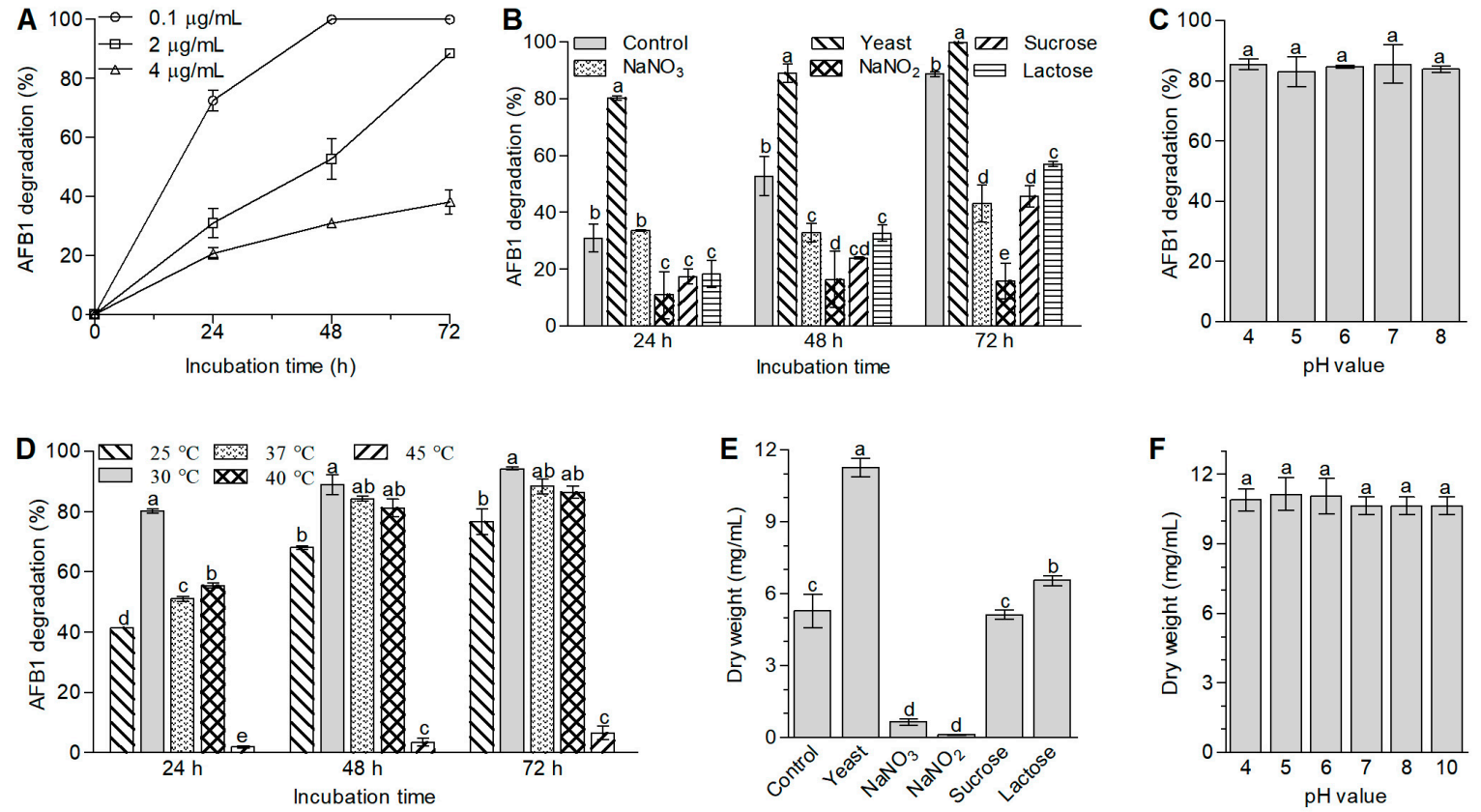

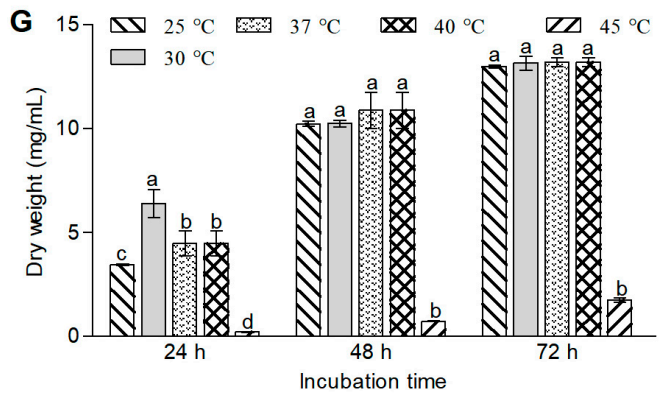

Figure 2. Effect of AFB1 concentrations (A), nutrients (B), initial pH value (C), and incubation temperature (D) on the degradation of AFB1 by A. niger RAF106 over $72 \mathrm{~h}$ of incubation and fungal biomass (E-G) after $A$. niger RAF106 was cultivated for $72 \mathrm{~h}$. The effects of nutrients were determined by replacing tryptone in the native $\mathrm{SDB}$ with yeast extract, $\mathrm{NaNO}_{3}$, or $\mathrm{NaNO}_{2}$ as a single nitrogen source and replacing glucose with lactose or sucrose as a single carbon source. The effects of the initial $\mathrm{pH}$ values and temperatures were investigated in the modified SDB with yeast extract. Different lowercase letters on the bars of each group indicate significant differences between the treatments (Tukey's HSD, $p<0.05$ ).

These changes suggested that $A$. niger RAF106 could be a potential AFB1-degrading strain that can be used in various environments with AFB1 contents ranging from 0.1 to $4 \mu \mathrm{g} / \mathrm{mL}$, $\mathrm{pH}$ values from 4 to 10 , and temperatures from 25 to $45^{\circ} \mathrm{C}$.

\subsection{AFB1 Degradation by Extracellular and Intracellular Extracts and Dead Cells of A. niger RAF106}

The AFB1 degradation activity of intracellular extracts from A. niger RAF106 was significantly stronger than that of the extracellular extracts and dead cells (Tukey's HSD, $p<0.05$ ). The contents of AFB1 were relatively stable in the dead cells and decreased slightly by $10.00-16.69 \%$ in the extracellular extracts over the $72 \mathrm{~h}$ incubation period, but the intracellular extracts could degrade AFB1 by $54.44 \%$ over $24 \mathrm{~h}$ of incubation, $78.54 \%$ for $48 \mathrm{~h}$ of incubation, and $83.64 \%$ for $72 \mathrm{~h}$ of incubation (Figure $3 \mathrm{~A}$ ). These findings demonstrated that intracellular extracts rather than extracellular extracts and adsorption played significant roles in the degradation of AFB1 mediated by A. niger RAF106. 

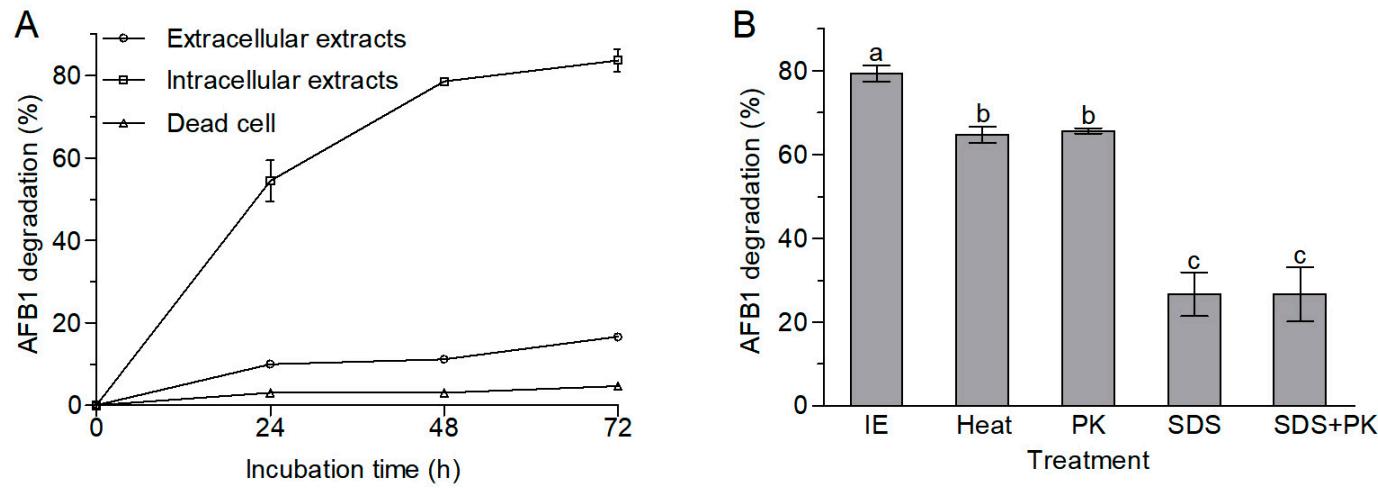

Figure 3. AFB1 degradation among the diverse cell components from A. niger RAF106. (A) Changes in the percentages of AFB1 degradation by extracellular extracts, intracellular extracts, and dead cells during $72 \mathrm{~h}$ of incubation with $2 \mu \mathrm{g} / \mathrm{mL}$ AFB1 at $30^{\circ} \mathrm{C}$. (B) Effects of heat, proteinase $\mathrm{K}$ (PK), sodium dodecyl sulfate (SDS), and SDS plus proteinase K on the degradation of AFB1 mediated by intracellular extracts (IE). After being treated with heat, proteinase $\mathrm{K}$, SDS, or SDS plus proteinase $\mathrm{K}$, the intracellular extracts were incubated with $2 \mu \mathrm{g} / \mathrm{mL}$ AFB1 at $30{ }^{\circ} \mathrm{C}$ for $48 \mathrm{~h}$. Different lowercase letters on the bars of each group indicate significant differences between the treatments (Tukey's HSD, $p<0.05$ ).

Moreover, the AFB1-degrading ability of the intracellular extracts declined significantly when the intracellular extracts were preconditioned with proteinase $\mathrm{K}$ and sodium dodecyl sulfate (SDS) $\left(F_{3,11}=240.33, p=0.0001\right)$. The percentage of AFB1 degradation decreased from $79.35 \%$ to $65.60 \%$ upon treatment with proteinase $\mathrm{K}$, and to $26.61 \%$ upon treatment with SDS or SDS plus proteinase $\mathrm{K}$ (Figure 3B). In addition, the intracellular extracts that were boiled for 20 min still degraded AFB1 by $64.68 \%$ (Figure $3 \mathrm{~B}$ ). These results strongly suggested that heat-stable intracellular enzymes or proteins might be the active ingredients for the degradation of AFB1 in A. niger RAF106.

\subsection{The Ames Test for Mutagenicity}

For the purpose of detoxifying AFB1 to less toxic metabolites, it is essential to assess the toxicity of the degradation products. In this study, the Ames test was used to measure the mutagenicity of the degradation products from AFB1 mediated by A. niger RAF106. Compared with the AFB1 group (positive control), the revertant colony-forming units (CFUs) in the AFB1-degrading medium extracts noticeably decreased by $56.10 \%$ for Salmonella typhimurium TA98 (Student's $t_{4}=25.51, p=0.0001$ ) and by $47.32 \%$ for $S$. typhimurium TA100 (Student's $t_{4}=7.91, p=0.0014$ ) (Figure 4 ), which were equivalent to that in the SDB group (negative control). The decreases in mutagenicity suggested that $A$. niger RAF106 might detoxify AFB1 into less toxic or non-toxic compounds.

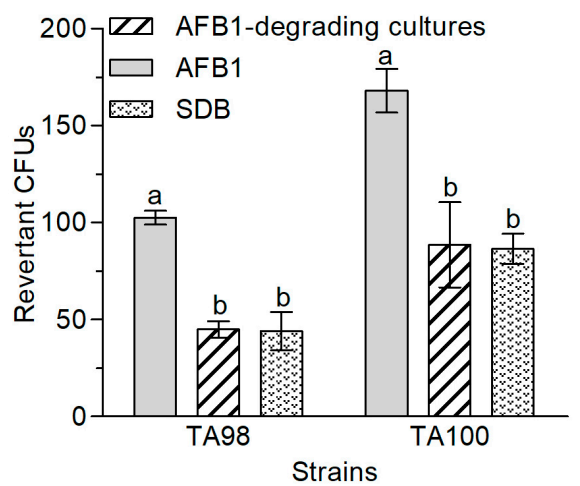

Figure 4. Reduction of AFB1 mutagenic effects by A. niger RAF106. Differences in revertant colony-forming units (CFUs) of S. typhimurium TA98 and TA100 between different groups. AFB1 group means extracts from the media supplemented with $20 \mu \mathrm{g}$ AFB1. The group of AFB1-degrading cultures 
refers to the culture extracts from the supernatant of the $72 \mathrm{~h}$ co-incubation of $20 \mu \mathrm{g}$ AFB1 and A. niger RAF106. The SDB group refers to extracts from the SDB media. Different lowercase letters on the bars of each group indicate significant differences between the treatments (Tukey's HSD, $p<0.05$ ).

\subsection{Analysis of the AFB1 Degradation Products}

Compared with AFB1 and the metabolites produced by A. niger RAF106 in SDB, four new peaks appeared in the AFB1-degrading cultures after $72 \mathrm{~h}$ of incubation (Figure 5), according to the high-performance liquid chromatography-quadrupole time-of-flight mass spectrometry (HPLC-Q-TOF-MS) data, and they corresponded with the molecular formulae $\mathrm{C}_{16} \mathrm{H}_{34} \mathrm{O}_{9}$ (m/z 370.23), $\mathrm{C}_{14} \mathrm{H}_{16} \mathrm{~N}_{2} \mathrm{O}_{3}(\mathrm{~m} / \mathrm{z} 260.12), \mathrm{C}_{23} \mathrm{H}_{48} \mathrm{O}_{8}(\mathrm{~m} / \mathrm{z} 452.34)$, and $\mathrm{C}_{14} \mathrm{H}_{16} \mathrm{~N}_{2} \mathrm{O}_{2}(\mathrm{~m} / \mathrm{z}$ 244.13) based on analysis with the DataAnalysis 4.0 (Bruker Daltonik, Bremen, Germany).
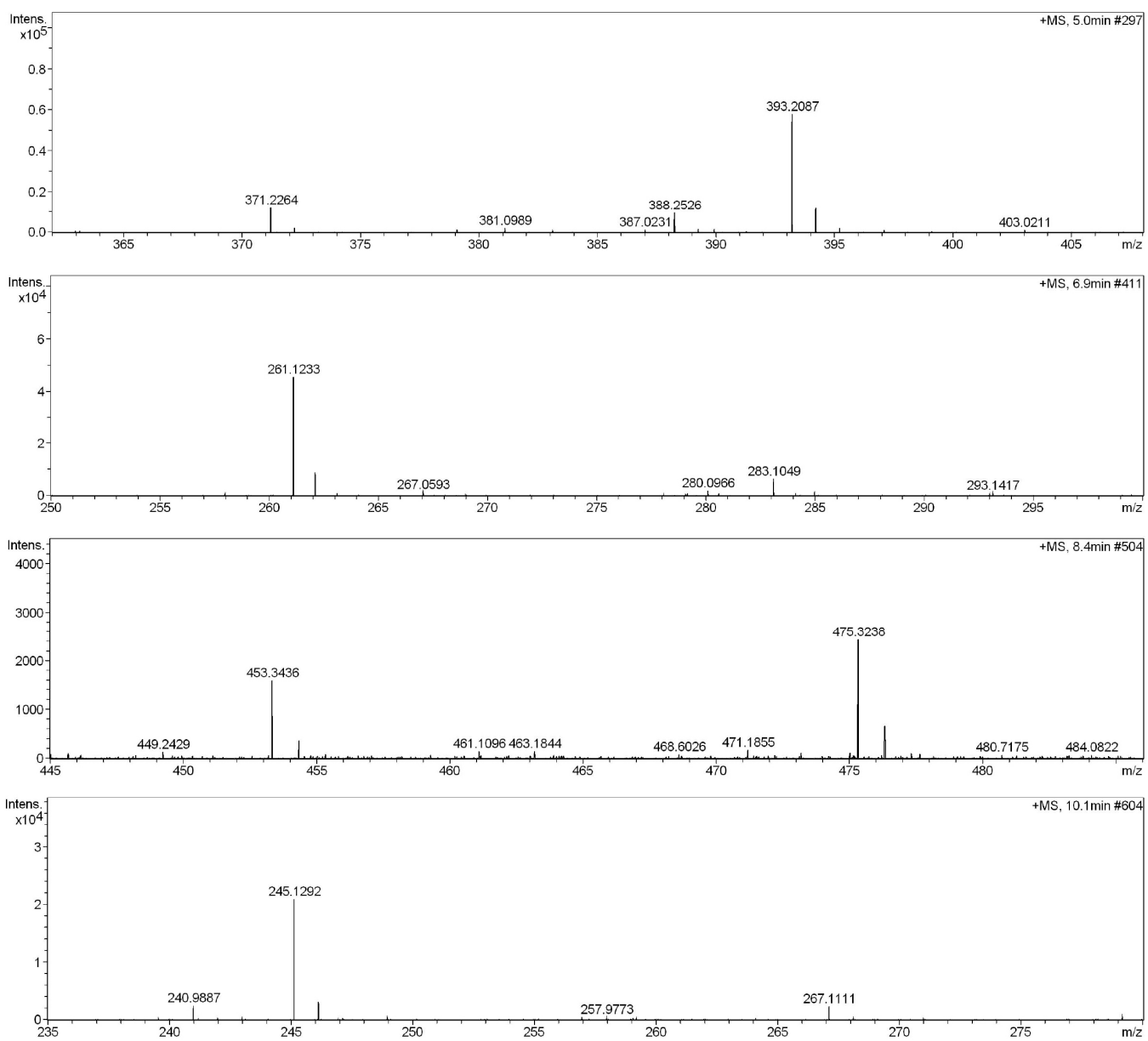

Figure 5. Mass spectra of degradation products for AFB1 by A. niger RAF106.

\subsection{Genomic Characteristics of A. niger RAF106}

The genome sequences of $A$. niger RAF106 were obtained using Illumina Hiseq (San Diego, CA, USA) and a PacBio system (Pacific Biosciences, Menlo Park, CA, USA). The assembled genome with a size of $35.09 \mathrm{Mb}$ and a GC content of $49.11 \%$ consisted of 10 contigs, 11,323 predicted genes, and 277 tRNAs (Figure 6A). The clusters of orthologous groups (COG) classification showed that 9175 genes were classified into four categories, including metabolism, cellular processes and signaling, information storage and processing, and function unknown (Figure 6B). 


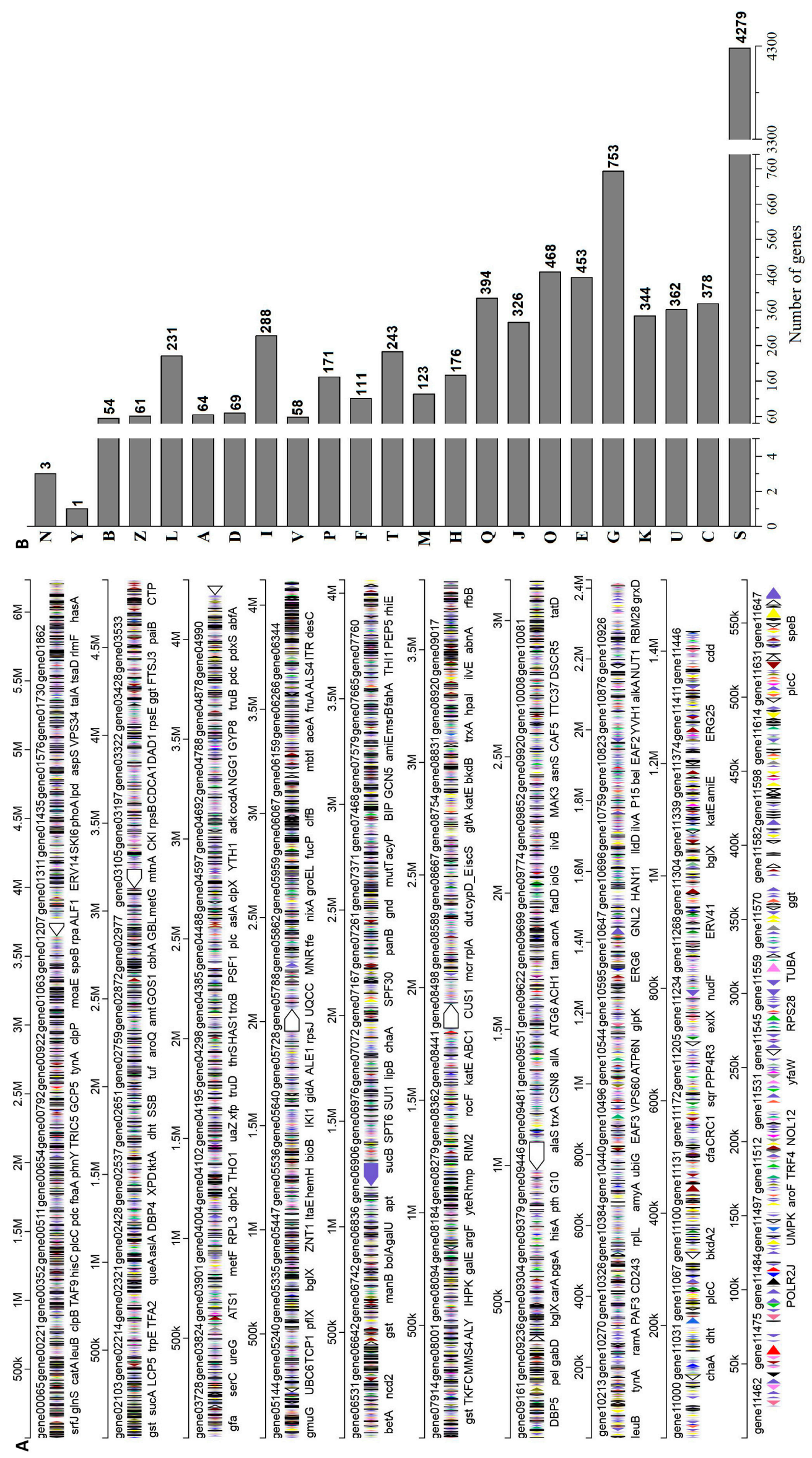

Figure 6. Genome map of A. niger RAF106 (A) and the clusters of orthologous groups (COG) classification of the genes in the genome $(\mathbf{B})$. The letters represent the following COG classifications: 
$\mathrm{C}$-energy production and conversion; $\mathrm{U}$-intracellular trafficking, secretion, and vesicular transport; S-function unknown; K-transcription; G—carbohydrate transport and metabolism; E-amino acid transport and metabolism; $\mathrm{O}$ - post-translational modification, protein turnover, and chaperones; J-translation, ribosomal structure, and biogenesis; Q-secondary metabolites biosynthesis, transport, and catabolism; H-coenzyme transport and metabolism; M—cell wall/membrane/envelope biogenesis; $\mathrm{T}$-signal transduction mechanisms; $\mathrm{F}$-nucleotide transport and metabolism; $\mathrm{P}$-inorganic ion transport and metabolism; V-defense mechanisms; I-lipid transport and metabolism; D—cell cycle control, cell division, and chromosome partitioning; A-RNA processing and modification; L-replication, recombination, and repair; Z—cytoskeleton; B-chromatin structure and dynamics; $\mathrm{Y}$-nuclear structure; $\mathrm{N}$-cell motility.

Some A. niger strains can produce mycotoxins, such as ochratoxin and fumonisin [30]; therefore, secondary metabolic gene clusters were analyzed using antiSMASH (Version 5.0.0, https://antismash. secondarymetabolites.org.) to investigate whether some mycotoxins might be synthesized in $A$. niger RAF106. Here, 88 secondary metabolic gene clusters were identified via an antiSMASH analysis, but only nine gene clusters harbored a $100 \%$ similarity to those of known secondary metabolites (Table 1). The gene clusters of mycotoxins, such as fumonisin and ochratoxin, were not found in the A. niger RAF106 genome. Moreover, the gene clusters of bioactive compounds, such as pyranonigrin E, TAN-1612, wortmanamide A, HC-toxin, clavaric acid, naphthopyrone, and aureobasidin A1, were found.

Table 1. Secondary metabolites predicted by the antiSMASH analysis of A. niger RAF106.

\begin{tabular}{|c|c|c|c|c|c|}
\hline Cluster Type & MIBiG ID * & Similarity & Cluster Type & MIBiG ID & Similarity \\
\hline \multicolumn{3}{|c|}{ Scaffold 1} & \multicolumn{3}{|c|}{ Scaffold 2} \\
\hline Aflatrem & BGC0000629 & $11 \%$ & Aflavarin & BGC0001304 & $40 \%$ \\
\hline Notoamide & BGC0000818 & $11 \%$ & Nidulanin A & BGC0001699 & $75 \%$ \\
\hline \multirow[t]{2}{*}{ Pyripyropene A } & BGC0001068 & $25 \%$ & Fusarielin $\mathrm{H}$ & BGC0001600 & $37 \%$ \\
\hline & Scaffold 3 & & Pyranonigrin E & BGC0001124 & $100 \%$ \\
\hline \multirow[t]{2}{*}{ Fumonisin } & BGC0000063 & $11 \%$ & & & \\
\hline & Scaffold 5 & & \multicolumn{3}{|c|}{ Scaffold 6} \\
\hline Azaphilone & BGC0000027 & $16 \%$ & HC-toxin & BGC0000370 & $100 \%$ \\
\hline Pyranonigrin E & BGC0001124 & $100 \%$ & Clavaric acid & BGC0001248 & $100 \%$ \\
\hline TAN-1612 & BGC0000156 & $100 \%$ & Naphthopyrone & BGC0000107 & $100 \%$ \\
\hline Wortmanamide A & BGC0001466 & $100 \%$ & Aflatrem & BGC0000629 & $17 \%$ \\
\hline Communesin & BGC0001205 & $12 \%$ & & & \\
\hline \multirow[t]{2}{*}{ Shearinine D } & BGC0001776 & $13 \%$ & \multicolumn{3}{|c|}{ Scaffold 9} \\
\hline & Scaffold 7 & & Aureobasidin A1 & BGC0000307 & $100 \%$ \\
\hline Citrinin & BGC0001338 & $18 \%$ & HC-toxin & BGC0000370 & $100 \%$ \\
\hline Aflatrem & BGC0000629 & $25 \%$ & Duclauxin & BGC0001578 & $42 \%$ \\
\hline Neurosporin A & BGC0001697 & $40 \%$ & & & \\
\hline
\end{tabular}

* MIBiG ID represents the identification number (ID) of clusterin MIBiG (Minimum Information about a Biosynthetic Gene cluster) database. The similarity between the predicted clusters and the clusters in MiBIG is expressed in parentheses.

Additionally, potential fungal virulence factors were BLASTed in the database of fungal virulence factors (DFVF) using Diamond (Version 0.8.35, https://github.com/bbuchfink/diamond). A total of 59 genes with a similarity of up to $80 \%$ were found; however, they were not virulence genes but rather regulatory genes that played essential roles in the regulation of fungal biological processes, including virulence in other fungi (Table 2). 
Table 2. Genes with a similarity of up to $80 \%$ found in A. niger RAF106 according to the database of fungal virulence factors.

\begin{tabular}{|c|c|c|}
\hline Gene ID & Annotation & Similarity \\
\hline \multicolumn{3}{|c|}{ Scaffold 1} \\
\hline gene00348 & Secondary metabolism regulator laeA & $83.1 \%$ \\
\hline gene00577 & $40 S$ ribosomal protein S27a & $100 \%$ \\
\hline gene00593 & Aspartic protease Pep2 & $87.7 \%$ \\
\hline gene00993 & Pyrophosphate phospho-hydrolase & $93.1 \%$ \\
\hline gene01168 & Cell division control protein 42 & $80.1 \%$ \\
\hline gene01307 & Phosphatidate cytidylyltransferase & $88.7 \%$ \\
\hline gene01444 & Transcriptional regulatory protein RPD3 & $87.8 \%$ \\
\hline gene01632 & Chitin synthase C & $80.9 \%$ \\
\hline gene01911 & Fatty acid desaturase & $92.8 \%$ \\
\hline \multicolumn{3}{|c|}{ Scaffold 2} \\
\hline gene02216 & 1,3-beta-glucan synthase component FKS1 & $89 \%$ \\
\hline gene02229 & Translation initiation factor eif- $2 \mathrm{~b}$ epsilon subunit & $83.4 \%$ \\
\hline gene02256 & Mitogen-activated protein kinase & $93.4 \%$ \\
\hline gene02307 & GTP-binding nuclear protein GSP1/Ran & $86 \%$ \\
\hline gene02534 & Histone $\mathrm{H} 3$ & $97.7 \%$ \\
\hline gene02609 & Guanine nucleotide-binding protein subunit $\alpha$ & $94.1 \%$ \\
\hline gene02632 & Mitogen-activated protein kinase hog1 & $95.1 \%$ \\
\hline gene02634 & $G$ protein complex alpha subunit $G p a B$ & $91.6 \%$ \\
\hline gene02843 & $\beta$-tubulin $\quad r$ & $97 \%$ \\
\hline gene03109 & Glucosamine-fructose-6-phosphate aminotransferase & $96.4 \%$ \\
\hline gene 03500 & Guanine nucleotide-binding protein subunit $\beta$ & $85.2 \%$ \\
\hline \multicolumn{3}{|c|}{ Scaffold 3} \\
\hline gene 03862 & Bifunctional tryptophan synthase TRPB & $85.2 \%$ \\
\hline gene03939 & Secretory pathway GDP dissociation inhibitor & $84.6 \%$ \\
\hline gene03951 & GlcNAc-1-P transferase & $81.3 \%$ \\
\hline gene03962 & Ribosomal RNA assembly protein mis3 & $88.3 \%$ \\
\hline gene04302 & Mitogen-activated protein kinase Fus3 & $85.5 \%$ \\
\hline gene04382 & Thioredoxin reductase Trr1/Trr2 & $85.3 \%$ \\
\hline gene04618 & $\alpha$-Tubulin & $92.3 \%$ \\
\hline gene04834 & Ubiquitin & $95.9 \%$ \\
\hline \multicolumn{3}{|c|}{ Scaffold 4} \\
\hline gene05492 & Tubulin $\alpha-1$ chain & $90.8 \%$ \\
\hline gene05524 & Ferrochelatase & $87.6 \%$ \\
\hline gene05596 & Citrate synthase Cit1 & $88.4 \%$ \\
\hline gene05603 & Malate synthase & $81.8 \%$ \\
\hline gene05712 & Imidazoleglycerol-phosphate dehydratase & $86.9 \%$ \\
\hline gene05752 & Mitochondrial import receptor subunit tom 40 & $86.5 \%$ \\
\hline gene05805 & Ornithine-N5-oxygenase & $81.4 \%$ \\
\hline gene 05876 & Peptidyl-prolyl cis-trans isomerase ssp-1 & $81.6 \%$ \\
\hline \multicolumn{3}{|c|}{ Scaffold 5} \\
\hline gene07009 & Rho-related protein rac1 & $85.1 \%$ \\
\hline gene07037 & Phosphoadenosine phosphosulfate reductase & $85.1 \%$ \\
\hline gene07271 & U1 snRNP splicing complex subunit & $94.6 \%$ \\
\hline gene07607 & Cell division control protein 2 & $90 \%$ \\
\hline \multicolumn{3}{|c|}{ Scaffold 6} \\
\hline gene08487 & Secretion related GTPase & $82.6 \%$ \\
\hline gene08506 & GTP-binding protein & $99 \%$ \\
\hline gene08568 & S-adenosylmethionine decarboxylase proenzyme & $83.4 \%$ \\
\hline gene 08576 & Glutamyl-tRNA synthetase & $83.4 \%$ \\
\hline gene08706 & Golgi transport protein Sly1 & $84.4 \%$ \\
\hline \multicolumn{3}{|c|}{ Scaffold 7} \\
\hline gene09163 & $1,3-\beta$-glucanosyltransferase Gel1 & $85.4 \%$ \\
\hline gene09291 & Homoserine O-acetyltransferase & $87.2 \%$ \\
\hline gene09449 & GTP-binding protein rhb1 & $95.2 \%$ \\
\hline gene09466 & Acetyl-CoA acetyltransferase & $92.2 \%$ \\
\hline gene09749 & Eukaryotic translation initiation factor 3 subunit & $80.6 \%$ \\
\hline
\end{tabular}


Table 2. Cont.

\begin{tabular}{ccc}
\hline Gene ID & Annotation & Similarity \\
\hline gene09874 & Aureobasidin resistance protein Aur1 & $92 \%$ \\
gene09879 & Sec14 cytosolic factor & $84.8 \%$ \\
gene09963 & DNA primase subunit Pri1 & $80.4 \%$ \\
& Scaffold 8 & \\
Gene10341 & Orotate phosphoribosyltransferase & $80.9 \%$ \\
Gene10380 & T-complex protein 1 & $82.8 \%$ \\
Gene10446 & Polyubiquitin & $98.7 \%$ \\
Gene10497 & Ribose-phosphate pyrophosphokinase & $86.1 \%$ \\
Gene10549 & Saccharopine dehydrogenase & $89.5 \%$ \\
Gene10566 & Mannose-1-phosphate guanyltransferase & $93.7 \%$ \\
\hline
\end{tabular}

All the data indicated that $A$. niger RAF106 produces beneficial substances but not mycotoxins and could serve as a beneficial and safe fungus to be applied in the processing of food and feed.

\section{Discussion}

Many A. niger strains are used extensively in food fermentation and the large-scale production of enzymes, organic acids, and bioactive compounds, which are also used in food and feed processing [24]. In addition, some $A$. niger strains, such as $A$. niger FS-Z1 and foodstuff-derived $A$. niger ND-1, could degrade AFB1 in a time-dependent manner [26,27]. Our results indicated that the tea-derived A. niger RAF106, with the exception of converting tea polyphenols into small molecules with high bioavailability [31], could also serve as a safe fungus to efficiently detoxify AFB1 time-dependently at ranges from 0.1 to $4 \mu \mathrm{g} / \mathrm{mL}$ over $72 \mathrm{~h}$ in food and feed processing, as discussed below.

First, the AFB1 degradation activity of $A$. niger RAF106 at a similar content of AFB1 and the same fermentation time was significantly higher than that in A. niger FS-Z1 and ND-1 [26,27]. Moreover, the hyphal growth of $A$. niger RAF106 was almost unaffected by AFB1 during the degradation of AFB1, which was consistent with the finding that the presence of AFB1 did not appear to inhibit the vegetative growth of any Pleurotus ostreatus strains [32]. Additionally, asexual conidiation promotes fungal dispersion. The decrease in the production of conidia caused by AFB1 could suppress the dispersion of $A$. niger RAF106 into other environments during AFB1 degradation.

Moreover, the efficiency of AFB1 degradation mediated by A. niger RAF106 was affected by nutrients and fermentation temperatures but not initial $\mathrm{pH}$ values. First, the acceleration of AFB1 degradation caused by yeast extract was consistent with that in the AFB1 degradation mediated by Myroides odoratimimus 3J2MO, but the inhibition of AFB1 degradation caused by sucrose and lactose, compared with glucose, is opposite to the phenomenon in M. odoratimimus 3J2MO and A. niger ND-1 [26,33]. Interestingly, the percentage of AFB1 degradation in the presence of yeast extract is similar to and even higher than that of most of the AFB1-degrading bacteria [34]. Changes in the AFB1 degradation caused by different nitrogen sources might have been due to the effects of different nitrogen sources on fungal growth. However, changes in the AFB1 degradation caused by lactose and sucrose differed from their effects on the fungal growth, suggesting that there were other regulators, such as the expression of biosynthetic genes and the enzyme production caused by nitrogen and carbon sources [31,35], that were involved in the regulation of AFB1 degradation in A. niger RAF106. Second, the optimal AFB1 degradation for A. niger RAF106 was also observed in the temperature range of $25-40{ }^{\circ} \mathrm{C}$, where the percentages of AFB1 degradation were similar to the degradation rates observed in Bacillus subtilis UTBSP1 and Bacillus velezensis DY3108 [21,36]. The lower AFB1 degradation activities at $25^{\circ} \mathrm{C}$ than those at $30-40{ }^{\circ} \mathrm{C}$ might be attributed to the decrease in fungal growth at $25^{\circ} \mathrm{C}$ following $24 \mathrm{~h}$ of incubation. Moreover, increased temperatures may have promoted the bioavailability of organic compounds and facilitated their biodegradation [37], which might also explain the lower AFB1 degradation activities at $25^{\circ} \mathrm{C}$. The lack of a statistically significant difference in the range of $30-40{ }^{\circ} \mathrm{C}$ is similar to the findings of Guan et al. [38], Mwakinyali et al. [33], and Shu et al. [21], where they 
pointed out that the degradation rates of AFB1 demonstrated no significant difference between 20 and $30{ }^{\circ} \mathrm{C}$ in Stenotrophomonas maltophilia 35-3, between 34 and $37^{\circ} \mathrm{C}$ in M. odoratimimus 3J2MO, and in the range of $28-30^{\circ} \mathrm{C}$ in $B$. velezensis DY3108. Furthermore, the optimal fungal growth for $A$. niger RAF106 was also observed in the temperature range of $25-40{ }^{\circ} \mathrm{C}$, which is in agreement with the previous reports on A. niger A-75 and A. niger ITAL $704[39,40]$. Additionally, the initial pH value is an important factor in fungal morphology, biomass accumulation, and metabolite formation [41,42]. In this study, the differences between the AFB1 degradation activities and the hyphal biomass at $\mathrm{pH}$ values of 4-8 were not significant. The similar AFB1 degradation among different initial $\mathrm{pH}$ values ranging from 4 to 8 was similar to the findings of $A$. niger ND-1 in which no significant differences between the percentage of AFB1 degradation at $\mathrm{pH}$ values of 6.5-8.0 were observed [26], but the phenomenon differed from the maximum degradation of AFB1 observed at $\mathrm{pH} 8.5$ and higher in M. odoratimimus 3J2MO, at $\mathrm{pH} 8$ for B. velezensis DY3108, at $\mathrm{pH} 6.0$ for Rhodicoccus erythropolis, and between $\mathrm{pH} 6.5$ and 7.5 for Myxococcus fulvus ANSM068 [21,33,43,44].

Furthermore, adsorption and degradation are the two primary approaches in the biocontrol of mycotoxin contamination [45]. In A. niger RAF106, the AFB1 degradation was mainly due to the enzymatic action of intracellular extracts, which is similar to that reported in Tetragenococcus halophilus CGMCC 3792, Candida versatilis CGMCC 3790, and Bacillus licheniformis BL010, but was opposite to that in A. niger ND-1, where AFB1 degradation was mainly caused by the involvement of enzymes from extracellular extracts [26,46-48]. In A. niger ND-1, heat treatment dramatically decreased the AFB1 degradation activities of the culture supernatant [26]. Interestingly, the percentage of AFB1 degradation mediated by intracellular extracts in this study remained at more than $50 \%$ after the intracellular extracts were boiled for $20 \mathrm{~min}$. The remaining AFB1 degradation activities were similar to those in Escherichia coli CG1061 but higher than those in C. versatilis CGMCC 3790, B. subtilis UTBSP1, and T. halophilus CGMCC $3792[36,46,47,49]$. These results suggested that intracellular enzymes or proteins with excellent thermostability were involved in the AFB1 degradation in A. niger RAF106.

Lastly, the process of using $A$. niger RAF106 to degrade AFB1 was safe. For one thing, the degradation products had no mutagenicity according to the Ames test, which was consistent with the findings in Aspergillus oryzae MAO103 and MAO104, B. licheniformis CFR1 and R. erythropolis [13,50,51]. It has been reported that the mutagenic effects of AFB1 were caused by both the lactone portion and the dihydrofuran moiety of the molecule $[6,7,13]$. The decreases in mutagenicity suggested that A. niger RAF106 might detoxify AFB1 into less toxic or non-toxic compounds without the lactone portion and/or the dihydrofuran moiety. For another thing, the genome data indicated that $A$. niger RAF106 does not produce mycotoxins or contain virulence genes. The absence of gene clusters of mycotoxins, such as fumonisin and ochratoxin in the A. niger RAF106 genome differed from the findings in A. niger NRRL 3122 and CBS 513.88 [29,52]. Moreover, the predicted metabolites from the genome of $A$. niger RAF106 showed the presence of pyranonigrin E, TAN-1612, wortmanamide A, HC-toxin, clavaric acid, naphthopyrone, and aureobasidin A1, which are active substances with anticancer, antimutagenic, antifungal, and/or antioxidant activities [53-58]. In addition, the genome also contained the genes for 12 cellulases, seven pectinases, and nine amylases (data not shown), which degrade complex polysaccharides and are important and widely used in food processing [25]. The size of the genome and the GC content are similar to those of A. niger L2 (36.45 Mb and 49.20\%, respectively), A. niger $\mathrm{H} 915$ (35.98 Mb and 49.20\%, respectively), A. niger An76 (34.88 Mb and 49.40\%, respectively), A. niger $\mathrm{SH} 2$ (34.63 Mb and 50.26\% respectively), and A. niger CBS 513.88 (34.02 $\mathrm{Mb}$ and $50.04 \%$, respectively) [29,59-61].

Overall, A. niger RAF106 and its intracellular extracts could serve as beneficial and safe bio-carriers to effectively detoxify AFB1 and are suitable for the various food and feed processing environments.

\section{Conclusions}

Aspergillus niger RAF106 could tolerate AFB1 and effectively detoxify it to compounds with less mutagenicity in environments with $\mathrm{pH}$ values from 4 to 10 and temperatures from 25 to $45^{\circ} \mathrm{C}$. 
More importantly, to the best of our knowledge, this is the first study to demonstrate more than $80 \%$ degradation of AFB1 over $24 \mathrm{~h}$ of incubation in A. niger strains. The degradation was attributed to intracellular proteins or enzymes with excellent thermostability. Moreover, a genomic analysis indicated that $A$. niger RAF106 is a safe and potentially useful fungus that lacks virulence genes and does not synthesize mycotoxins. However, further studies are needed to illuminate the structures of the degradation products and the enzymatic characteristics of the intracellular enzymes. In summary, A. niger RAF106 could potentially be a safe, beneficial, and commercial fungus to be applied to detoxify AFB1 in food and feed processing and industries.

\section{Material and Methods}

\subsection{Fungal Strains and Culture Conditions}

Aspergillus niger RAF106 (CGMCC NO.9608), the catechin-transforming fungus isolated from $\mathrm{Pu}$-erh tea [31], was cultivated in potato dextrose agar (PDA) at $30{ }^{\circ} \mathrm{C}$ to produce conidia, Sabouraud dextrose broth (1\% tryptone and $4 \%$ glucose, $\mathrm{pH} 7.0)$ to degrade AFB1, and SDA (1\% tryptone, $4 \%$ glucose, and $2 \%$ agar, $\mathrm{pH} 7.0$ ) to detect the effect of AFB1 on the conidiation capacity. The conidia were harvested by washing the mature culture on the medium with sterilized $0.02 \%$ Tween 80 . Salmonella typhimurium TA98 and TA100 purchased from Moltox (Boone, NC, USA) were cultivated in beef extract peptone medium at $37^{\circ} \mathrm{C}$ for the Ames test.

\subsection{AFB1 Degradation by A. niger RAF106 in Liquid Culture}

A suspension of $500 \mu \mathrm{L}$ of $10^{8}$ conidia/mL (the same is used below unless specified) was incubated in $100 \mathrm{~mL}$ SDB supplemented with gradient concentrations of AFB1 $(0.1-4 \mu \mathrm{g} / \mathrm{mL})$ purchased from J\&K Scientific (Beijing, China) for 3 days at $30^{\circ} \mathrm{C}$ via shaking at $180 \mathrm{rpm}$. During 3 days of incubation with shaking at $30{ }^{\circ} \mathrm{C}$, sterile SDB with gradient concentrations of AFB1 was used as the control. The supernatant was extracted daily using half the volume of chloroform three times by shaking at $180 \mathrm{rpm}$, as previously described [38,46,49], and the chloroform fractions were evaporated and dissolved using dimethyl sulfoxide (DMSO, Sigma-Aldrich, St. Louis, MO, USA). The redissolved solution was filtered through a $0.22 \mu \mathrm{m}$ pore filter (Merck-Millipore, Darmstadt, Germany) and stored at $-20{ }^{\circ} \mathrm{C}$ for HPLC detection. Using chloroform extraction, $94-96 \%$ of the AFB1 was recovered from the liquid culture. All of the experiments were conducted in triplicate.

\subsection{Quantification of AFB1 Using HPLC}

AFB1 and the subsequent degradation products were analyzed using HPLC (Waters Alliance 2695, Milford, MA, USA) equipped with a YMC C18 column $(250 \times 4.6 \mathrm{~mm}, 5 \mu \mathrm{m})$ and a UV detector set at $360 \mathrm{~nm}$ [62]. A volume of $10 \mu \mathrm{L}$ of samples was injected and eluted with the mobile solvent consisting of water/methanol/acetonitrile $(48: 40: 12, \mathrm{v} / \mathrm{v} / \mathrm{v})$ at a constant flow rate of $0.8 \mathrm{~mL} / \mathrm{min}$ at $30^{\circ} \mathrm{C}$. The limit of detection (LOD) was $0.01 \mu \mathrm{g} / \mathrm{mL}$ AFB1 and the limit of quantitation was $0.05 \mu \mathrm{g} / \mathrm{mL}$ AFB1 under the experimental conditions used. The concentration of AFB1 was determined using external calibration curves of the standard AFB1 solution at different concentrations. The percentage of AFB1 degradation was calculated using the following formula: AFB1 degradation $(\%)=(1-$ remaining AFB1 in sample/total AFB1 in control sample) $\times 100$.

\subsection{Changes in Fungal Growth and Aerial Conidiation Caused by AFB1 in A. niger RAF106}

The fungal growth was measured first by assessing the fungal biomass when aliquots of conidial suspension were incubated in SDB and SDB with $2 \mu \mathrm{g} / \mathrm{mL}$ AFB1 for 3 days at $30^{\circ} \mathrm{C}$ while shaking at $180 \mathrm{rpm}$. Briefly, the hyphae were collected daily, dried at $60^{\circ} \mathrm{C}$, and weighed. The data was converted to the weight per $\mathrm{mL}$ culture. Second, aliquots of $1 \mu \mathrm{L}$ of a $10^{6}$ conidia/mL suspension were spotted centrally onto plates (60 mm diameter) of SDA and SDA supplemented with $2 \mu \mathrm{g} / \mathrm{mL}$ AFB1 at $30^{\circ} \mathrm{C}$. 
After 3 days, the diameter of each colony was estimated using two measurements taken perpendicular to each other across the center of the colony. All of the experiments were conducted in triplicate.

The aerial conidiation capacity was quantified by spreading $50 \mu \mathrm{L}$ of a $10^{7}$ conidia/mL suspension on SDA plates (60 mm diameter) and SDA plates with $2 \mu \mathrm{g} / \mathrm{mL}$ AFB1 followed by 3 days of cultivation at $30^{\circ} \mathrm{C}$. On days 1,2 , and 3 , all the conidia from each plate were washed and harvested with $5 \mathrm{~mL}$ of $0.02 \%$ Tween 80 using vibration. The concentration of conidia in the suspension was determined using a hemocytometer and converted to the number of conidia per square centimeter of plate culture. All of the experiments were conducted in triplicate.

\subsection{Effects of Nutrients, $p H$, and Temperature on AFB1 Degradation and Fungal Growth}

The effects of the nutrients on AFB1 degradation were determined in modified SDB. The modified media were prepared by replacing tryptone in $\mathrm{SDB}$ with yeast extract, $\mathrm{NaNO}_{3}$, or $\mathrm{NaNO}_{2}$ as the single nitrogen source and replacing glucose with lactose or sucrose as the single carbon source. The effects of $\mathrm{pH}$ and temperature were determined in modified SDB with yeast extract by adjusting the initial $\mathrm{pH}$ values to $4.0,5.0,6.0,7.0,8.0$, or 10.0 and by setting the initial temperature to $25,30,37,40$, or $45^{\circ} \mathrm{C}$. Aliquots of the conidial suspensions were added to the modified SDB with $2 \mu \mathrm{g} / \mathrm{mL}$ AFB1 and incubated for $72 \mathrm{~h}$ with constant shaking (180 rpm). Correspondingly, the modified SDB with 2 $\mu \mathrm{g} / \mathrm{mL}$ AFB1 in each incubation was used as the control. The residual AFB1 was determined using HPLC analysis. In addition, the fungal growth was also investigated by measuring the biomass. All of the experiments were conducted in triplicate.

\subsection{AFB1 Degradation by Extracellular Extracts, Intracellular Extracts, and Dead Cells}

Aliquots of conidial suspensions were pre-cultivated in SDB at $30{ }^{\circ} \mathrm{C}$ with shaking at $180 \mathrm{rpm}$ for $48 \mathrm{~h}$. After centrifugation at $12,000 \mathrm{rpm}$ at $4^{\circ} \mathrm{C}$ for $15 \mathrm{~min}$, the supernatant and cells were collected. The supernatant was filtered with a $0.22 \mu \mathrm{m}$ pore filter and served as the extracellular extracts for the degradation of AFB1. The cells were washed three times with a $10 \mathrm{mM}$ phosphate buffer (pH 7.4), ground in liquid nitrogen, suspended in an equal volume of a $10 \mathrm{mM}$ phosphate buffer ( $\mathrm{pH} 7.4$ ), and centrifuged for $20 \mathrm{~min}$ at $12,000 \mathrm{rpm}$ at $4{ }^{\circ} \mathrm{C}$. The supernatant was filtered with the $0.22 \mu \mathrm{m}$ pore filter and served as the intracellular extracts for the degradation of AFB1. Moreover, the cells that had been washed three times were boiled for $20 \mathrm{~min}$, resuspended in an equal volume of $10 \mathrm{mM}$ phosphate buffer ( $\mathrm{pH} 7.4$ ), and served as the dead cells for the degradation of AFB1. The extracellular extracts, intracellular extracts, and dead cells were incubated with $2 \mu \mathrm{g} / \mathrm{mL}$ AFB1 at $30{ }^{\circ} \mathrm{C}$ with shaking at $180 \mathrm{rpm}$. Non-incubated cultures (SDB for extracellular extracts and phosphate buffer for intracellular extracts and dead cells) supplemented with $2 \mu \mathrm{g} / \mathrm{mL}$ AFB1 were used as the control, and all the variables in the control groups were similar to those for the corresponding extracts and dead cells. At $24 \mathrm{~h}$ intervals, the residual AFB1 was tested as described above. All of the experiments were conducted in triplicate.

\subsection{Effects of Proteinase K, SDS, and Heat Treatment on the Degradation of AFB1}

The effects of proteinase K (a serine protease, purchased from Sangon, Shanghai, China), SDS (purchased from Fuyu Fine Chemical Co., Ltd., Tianjin, China), and heat treatment on AFB1 degradation were performed to investigate whether the degradation of AFB1 was mediated by thermostable enzymes or proteins in A. niger RAF106. The intracellular extracts were boiled for $20 \mathrm{~min}$ and treated with $1 \mathrm{mg} / \mathrm{mL}$ proteinase $\mathrm{K}, 1 \% \mathrm{SDS}$, or SDS plus proteinase $\mathrm{K}$ for $6 \mathrm{~h}$ at $30^{\circ} \mathrm{C}$. Subsequently, each sample was incubated with $2 \mu \mathrm{g} / \mathrm{mL}$ AFB1 at $30^{\circ} \mathrm{C}$ with constant shaking (180 rpm), and phosphate buffer with $2 \mu \mathrm{g} / \mathrm{mL}$ AFB1 was used as the control. After $48 \mathrm{~h}$, the residue of AFB1 was monitored as described above. All of the experiments were conducted in triplicate. 


\subsection{Analysis of the AFB1 Metabolites Using HPLC-Q-TOF-MS}

After a 72-h incubation of $A$. niger RAF106 in SDB with $2 \mu \mathrm{g} / \mathrm{mL}$ AFB1, the metabolites were extracted with chloroform as described above and separated using an Agilent 1260 series HPLC system equipped with an auto-injector and quaternary HPLC pump (Agilent Technologies, Santa Clara, CA, USA) $[38,46,49]$. The chromatography was conducted on a Phenomenex Luna 5 u C18(2)100A column $(250 \times 4.60 \mathrm{~mm}, 5 \mu \mathrm{m})$ (Torrance, CA, USA). Samples $(10 \mu \mathrm{L})$ were injected and eluted with the mobile solvent that contained $45: 55$ of methanol and water $(\mathrm{v} / \mathrm{v})$ with $0.1 \%$ formic acid. The total run time was $30 \mathrm{~min}$ with a flow rate of $0.5 \mathrm{~mL} / \mathrm{min}$. An MS analysis was performed with a Bruker maXis ESI Q-TOF (Bruker Daltonik, Bremen, Germany). The acquisition parameters were as follows: the capillary voltage was set at $4.5 \mathrm{kV}$ in the positive ionization mode and the dry temperature was $180^{\circ} \mathrm{C}$. The drying gas flowed at $5.0 \mathrm{~L} / \mathrm{min}$ and the nebulizer was at $0.8 \mathrm{bar}$. The MS was operated in full scan mode, and the data were collected within the range of $\mathrm{m} / \mathrm{z}$ 100-2000. Samples extracted from SDB with $2 \mu \mathrm{g} / \mathrm{mL}$ AFB1 were used as the positive control and samples extracted from SDB and cultures of $A$. niger RAF106 in SDB were used as the negative control.

\subsection{Ames Mutagenicity Assay}

The Salmonella (Ames) test with metabolic activation was used as a proxy to evaluate the mutagenicity of the degradation products [63]. The Ames assay was conducted with the S9 Enzyme Activation Kit (Iphase Pharma Service, Beijing, China) that is based on the validated Ames bacterial reverse mutation assay, according to the manufacturer's instructions. Briefly, the degradation products extracted from a $72 \mathrm{~h}$ culture co-incubated with A. niger RAF106 and AFB1 were incubated with S. typhimurium TA98 or TA 100 at $37^{\circ} \mathrm{C}$. After $48 \mathrm{~h}$, the number of $S$. typhimurium colonies was recorded, and the data were shown as the number of revertant CFUs. A sample extracted from SDB with AFB1 was used as the positive control and extracts from SDB were used as the negative control. The manufacturer's instructions indicated that the revertant CFUs must be controlled within the range from 150 to 250; therefore, the dose-dependent curve of the revertant CFUs caused by AFB1 was first established. A concentration of $20 \mathrm{ng} / \mathrm{plate}$ of AFB1 was chosen as the mutagenic dose based on the curve. All of the experiments were conducted in triplicate.

\subsection{Genome Sequencing and Analysis}

Genomic DNA was extracted using an Omega Fungal DNA Kit D3390-02 (Qiagen, Hilden, Germany) according to the manufacturer's instructions, and genome sequencing was performed with a combination of the PacBio Sequel Single-Molecule Real-Time (SMRT) (Pacific Biosciences, Menlo Park, CA, USA) and Illumina sequencing platforms (HiSeq X Ten; Illumina, San Diego, CA, USA). After clean data were obtained, the reads were then assembled into contigs using CANU (Version 1.7, http://canu.readthedocs.io/en/latest/). Finally, error correction of the PacBio assembly results was performed using the Illumina reads. The sequence data for A. niger RAF106 was deposited at the US National Center for Biotechnology Information (NCBI) under the accession number RIBO00000000.

Identification of the predicted coding sequences (CDSs) was performed using Maker2 (Version 2.31.9, http://www.yandell-lab.org/software/maker.html), and tRNA-scan-SE (Version 2.0, http://trna. ucsc.edu/software/) was used for tRNA searching. The predicted CDSs were annotated from the databases of NR (Non-Redundant Protein Sequence Database), Swiss-Prot, Pfam, Go Ontology (GO), COG, and Kyoto Encyclopedia of Genes and Genomes (KEGG) using sequence alignment tools, namely, Basic Local Alignment Search Tool (BLAST; Version 2.3.0, ftp://ftp.ncbi.nlm.nih.gov/blast/ executables/blast+/2.3.0/), Diamond, and HMMER (Version 3.1b2, http://www.hmmer.org/). Briefly, each set of query proteins were aligned with the databases, and annotations of the best-matched subjects (E-value $<10^{-5}$ ) were obtained for the gene annotation. Secondary metabolite clusters were predicted using antiSMASH, and all of the analyses were performed using the I-Sanger Cloud Platform (www.i-sanger.com) from Shanghai Majorbio (Shanghai, China). 


\subsection{Data Analysis}

Results from three replicates were expressed as mean \pm standard deviation (SD), and the data analysis was subjected to one-factor analysis of variance (ANOVA), followed by Tukey's HSD test. In addition, Student's $t$-test and the $F$-test were applied to compare the differences between two samples and between three and more samples, respectively. Results were considered to be statistically significant when ${ }^{*} p<0.05$ in all experiments.

Author Contributions: Conceptualization, Q.F. and J.W.; methodology, J.C.; validation, T.L.; formal analysis, Z.L.; investigation, Q.F. and M.D.; resources, X.F. and J.W.; data curation, M.D.; writing-original draft preparation, Q.F. and J.W.; writing-review and editing, J.W., L.W., and Q.Z.; visualization, T.L. and J.W.; supervision, Y.Z. All authors have read and agreed to the published version of the manuscript.

Funding: This work was financially supported by the Key Area Research and Development Program of Guangdong Province (2018B020206001 and 2020B020226008), the National Natural Science Foundation of China (31600060, 31671855, and 31871790), the Guangzhou Science and Technology Research Projects (201904010274), the Yangjiang Science and Technology Research Projects (SDZX2020030), and the opening foundation from the State Key Laboratory of Applied Microbiology Southern China, Guangdong Institute of Microbiology (SKLAM003-2018).

Conflicts of Interest: The authors declare that there was no conflict of interest.

\section{References}

1. Lee, H.J.; Ryu, D. Worldwide occurrence of mycotoxins in cereals and cereal-derived food products: Public health perspectives of their co-occurrence. J. Agric. Food Chem. 2017, 65, 7034-7051. [CrossRef] [PubMed]

2. Eskola, M.; Kos, G.; Elliott, C.T.; Hajšlová, J.; Mayar, S.; Krska, R. Worldwide contamination of food-crops with mycotoxins: Validity of the widely cited 'FAO estimate' of 25\%. Crit. Rev. Food Sci. 2019, 1549-7852. [CrossRef] [PubMed]

3. Nugraha, A.; Khotimah, K.; Rietjens, I.M.C.M. Risk assessment of aflatoxin $B_{1}$ exposure from maize and peanut consumption in Indonesia using the margin of exposure and liver cancer risk estimation approaches. Food Chem. Toxicol. 2018, 113, 134-144. [CrossRef] [PubMed]

4. Cui, A.; Hua, H.; Shao, T.; Song, P.; Kong, Q.; Luo, T.; Jiang, Y. Aflatoxin B B $_{1}$ induces Src phosphorylation and stimulates lung cancer cell migration. Tumour Biol. 2015, 36, 6507-6513. [CrossRef]

5. Lahoum, A.; Verheecke-Vawssen, C.; Bouras, N.; Sabaou, N.; Mathieu, F. Taxonomy of mycelial actinobacteria isolated from Saharan soils and their effiency to reduce aflatoxin $\mathrm{B}_{1}$ content in a solid-based medium. Ann. Microbiol. 2017, 67, 231-237. [CrossRef]

6. Lee, L.S.; Dunn, J.J.; Delucca, A.J.; Ciegler, A. Role of lactone ring of aflatoxin $\mathrm{B}_{1}$ in toxicity and mutagenicity. Experientia 1981, 37, 16-17. [CrossRef]

7. Wogan, G.; Edwards, G.; Newberne, P. Structure-activity relationships in toxicity and carcinogenicity of aflatoxins and analogs. Cancer Res. 1971, 31, 1936-1942.

8. Cullen, J.M.; Ruebner, B.H.; Hsieh, L.S.; Hyde, D.M.; Hsieh, D.P. Carcinogenicity of dietary aflatoxin $\mathrm{M}_{1}$ in male fischer rats compared to aflatoxin $\mathrm{B}_{1}$. Cancer Res. 1987, 47, 1913-1917.

9. Luongo, D.; Russo, R.; Balestrieri, A.; Marzocco, S.; Bergamo, P.; Severino, L. In vitro study of $\mathrm{AFB}_{1}$ and $\mathrm{AFM}_{1}$ effects on human lymphoblastoid Jurkat T-cell model. J. Immunotoxicol. 2013, 11, 353-358. [CrossRef]

10. Pitt, J.I.; Miller, J.D. A concise history of mycotoxin research. J. Agric. Chem. 2017, 65, 7021-7033. [CrossRef]

11. Wu, F.; Mitchell, N.J. How climate change and regulations can affect the economics of mycotoxins. World Mycotoxin J. 2016, 9, 653-663. [CrossRef]

12. Williams, J.H.; Phillips, T.D.; Jolly, P.E.; Stiles, J.K.; Jolly, C.M.; Aggarwal, D. Human aflatoxicosis in developing countries: A review of toxicology, exposure, potential health consequences, and interventions. Am. J. Clin. Nutr. 2004, 80, 1106-1122. [CrossRef] [PubMed]

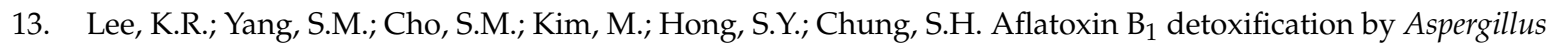
oryzae from Meju, a traditional Korean fermented soybean starter. J. Microbiol. Biotechnol. 2017, 27, 57-66. [CrossRef] [PubMed]

14. Mishra, H.N.; Das, C. A review on biological control and metabolism of aflatoxin. Front. Pharmacol. 2003, 43, 245-264. [CrossRef] [PubMed]

15. Wu, Q.; Jezkova, A.; Yuan, Z.; Pavlikova, L.; Dohnal, V.; Kuca, K. Biological degradation of aflatoxins. Drug Metab. Rev. 2009, 41, 1-7. [CrossRef] [PubMed] 
16. Chen, Y.; Kong, Q.; Chi, C.; Shan, S.; Guan, B. Biotransformation of aflatoxin B-1 and aflatoxin G(1) in peanut meal by anaerobic solid fermentation of Streptococcus thermophilus and Lactobacillus delbrueckii subsp. bulgaricus. Int. J. Food Microbiol. 2015, 211, 1-5. [CrossRef] [PubMed]

17. Samuel, M.S.; Sivaramakrishna, A.; Mehta, A. Degradation and detoxification of aflatoxin $B_{1}$ by Pseudomonas putida. Int. Biodeter. Biodegrad. 2014, 86, 202-209. [CrossRef]

18. Eshelli, M.; Harvey, L.; Edrada-Ebel, R.; McNeil, B. Metabolomics of the bio-degradation process of aflatoxin $\mathrm{B}_{1}$ by actinomycetes at an initial $\mathrm{pH}$ of 6.0. Toxins 2015, 7, 439-456. [CrossRef]

19. Wang, J.; Ogata, M.; Hirai, H.; Kawagishi, H. Detoxification of aflatoxin $B_{1}$ by manganese peroxidase from the white-rot fungus Phanerochaete sordida YK-624. FEMS Microbiol. Lett. 2011, 314, 164-169. [CrossRef]

20. Ji, C.; Fan, Y.; Zhao, L. Review on biological degradation of mycotoxins. Anim. Nutr. 2016, 2, 127-133. [CrossRef]

21. Shu, X.; Wang, Y.; Zhou, Q.; Li, M.; Hu, H.; Ma, Y.; Chen, X.; Ni, J.; Zhao, W.; Huang, S.; et al. Biological degradation of Aflatoxin B-1 by cell-free extracts of Bacillus velezensis DY3108 with broad pH stability and excellent thermostability. Toxins 2018, 10, 330. [CrossRef] [PubMed]

22. Adebo, O.A.; Njobeh, P.B.; Sidu, S.; Tlou, M.G.; Mavumengwana, V. Aflatoxin $B_{1}$ degradation by liquid cultures and lysates of three bacterial strains. Int. J. Food Microbiol. 2016, 233, 11-19. [CrossRef] [PubMed]

23. Cairns, T.C.; Nai, C.; Meyer, V. How a fungus shapes biotechnology: 100 years of Aspergillus niger research. Fungal Biol. Biotechnol. 2018, 5, 13. [CrossRef] [PubMed]

24. Park, H.S.; Jun, S.C.; Han, K.H.; Hong, S.B.; Yu, J.H. Diversity, application, and synthetic biology of industrially important Aspergillus fungi. Adv. Appl. Microbiol. 2017, 100, 161-202.

25. Ma, Y.; Ling, T.; Su, X.; Jiang, B.; Nian, B.; Chen, L.; Liu, M.; Zhang, Z.; Wang, D.; Mu, Y.; et al. Integrated proteomics and metabolomics analysis of tea leaves fermented by Aspergillus niger, Aspergillus tamarii and Aspergillus fumigatus. Food Chem. 2020, 334, 127560. [CrossRef]

26. Zhang, W.; Xue, B.; Li, M.; Mu, Y.; Shan, A. Screening a strain of Aspergillus niger and optimization of fermentation conditions for degradation of Aflatoxin $B_{1}$. Toxins 2014, 6, 3157-3172. [CrossRef]

27. Sun, X.; Sun, C.; Zhang, X.; Zhang, H.; Tang, L. Aflatoxin $B_{1}$ decontamination by UV-mutated live and immobilized Aspergillus niger. Food Control 2015, 61, 235-242. [CrossRef]

28. Mann, R.; Rehm, H.J. Degradation products from aflatoxin $\mathrm{B}_{1}$ by Corynebacterium rubrum, Aspergillus niger, Trichoderma viride and Mucor ambiguus. Appl. Microbiol. Biotechnol. 1976, 2, 297-306.

29. Andersen, M.R.; Salazar, M.P.; Schaap, P.J.; Van de Vondervoort, P.J.I.; Culley, D.; Thykaer, J.; Frisvad, J.C.; Nielsen, K.F.; Albang, R.; Albermann, K.; et al. Comparative genomics of citric-acid-producing Aspergillus niger ATCC 1015 versus enzyme-producing CBS 513.88. Genome Res. 2011, 21, 885-897. [CrossRef]

30. Frisvad, J.C.; Møller, L.L.H.; Larsen, T.O.; Kumar, R.; Arnau, J. Safety of the fungal workhorses of industrial biotechnology: Update on the mycotoxin and secondary metabolite potential of Aspergillus niger, Aspergillus oryzae, and Trichoderma reesei. Appl. Microbiol. Biotechnol. 2018, 102, 9481-9515. [CrossRef]

31. Fang, X.; Du, M.; Liu, T.; Fang, Q.; Liao, Z.; Zhong, Q.; Chen, J.; Meng, X.; Zhou, S.; Wang, J. Changes in the biotransformation of green tea catechins induced by different carbon and nitrogen sources in Aspergillus niger RAF106. Front. Microbiol. 2019, 10, 2521. [CrossRef] [PubMed]

32. Jackson, L.W.; Pryor, B.M. Degradation of aflatoxin $B_{1}$ from naturally contaminated maize using the edible fungus Pleurotus ostreatus. AMB Express 2017, 7, 110. [CrossRef] [PubMed]

33. Mwakinyali, S.E.; Ming, Z.; Xie, H.; Zhang, Q.; Li, P. Investigation and characterization of Myroides odoratimimus Strain 3J2MO aflatoxin B 1 degradation. J. Agric. Food Chem. 2019, 67, 4595-4602. [CrossRef] [PubMed]

34. Verheecke, C.; Liboz, T.; Mathieu, F. Microbial degradation of aflatoxin $\mathrm{B}_{1}$ : Current status and future advances. Int. J. Food Microbiol. 2016, 237, 1-9. [CrossRef] [PubMed]

35. Brzonkalik, K.; Herrling, T.; Syldatk, C.; Neumann, A. The influence of different nitrogen and carbon sources on mycotoxin production in Alternaria alternate. Int. J. Food Microbiol. 2011, 147, 120-126. [CrossRef] [PubMed]

36. Farzaneh, M.; Shi, Z.; Ghassempour, A.; Sedaghat, N.; Ahmadzadeh, M.; Mirabolfathy, M.; Javan-Nikkhah, M. Aflatoxin $\mathrm{B}_{1}$ degradation by Bacillus subtilis UTBSP1 isolated from pistachio nuts of Iran. Food Control 2012, 23, 100-106. [CrossRef]

37. Müller, R.; Antranikian, G.; Maloney, S.; Sharp, R. Thermophilic degradation of environmental pollutants. In: Biotechnology of Extremophiles. Adv. Biochem. Eng. Biotechnol. 2007, 61, 155-169. 
38. Guan, S.; Cheng, J.; Ting, Z.; Junxia, L.; Qiugang, M.; Tiangui, N. Aflatoxin B 1 degradation by Stenotrophomonas Maltophilia and other microbes selected using coumarin medium. Int. J. Mol. Sci. 2008, 9, 1489-1503. [CrossRef]

39. Alborch, L.; Bragulat, M.R.; Abarca, M.L.; Cabañes, F.J. Effect of water activity, temperature and incubation time on growth and ochratoxin a production by Aspergillus niger and Aspergillus carbonarius on maize kernels. Int. J. Food Microbiol. 2011, 147, 53-57. [CrossRef]

40. Héctor, P.; Hiromi, T.M.; Minoru, H.J.; De, M.H.C. Growth of Aspergillus ochraceus, A. carbonarius and A. niger on culture media at different water activities and temperatures. Braz. J. Microbiol. 2005, 36, 24-28.

41. Colin, V.; Baigorí, M.; Pera, L. Tailoring fungal morphology of Aspergillus niger MYA 135 by altering the hyphal morphology and the conidia adhesion capacity: Biotechnological applications. AMB Express 2013, 3, 27. [CrossRef] [PubMed]

42. Shu, C.H.; Lung, M.Y. Effect of $\mathrm{pH}$ on the production and molecular weight distribution of exopolysaccharide by Antrodia camphorate in batch cultures. Process Biochem. 2004, 39, 931-937. [CrossRef]

43. Kong, Q.; Zhai, C.; Guan, B.; Li, C.; Shan, S.; Yu, J. Mathematic modeling for optimum conditions on aflatoxin $\mathrm{B}_{1}$ degradation by the aerobic bacterium Rhodococcus erythropolis. Toxins 2012, 4, 1181-1195. [CrossRef] [PubMed]

44. Zhao, L.H.; Guan, S.; Gao, X.; Ma, Q.G.; Lei, Y.P.; Bai, X.M.; Ji, C. Preparation, purification and characteristics of an aflatoxin degradation enzyme from Myxococcus fulvus ANSM068. J. Appl. Microbiol. 2010, 110, 147-155. [CrossRef]

45. Hathout, A.S.; Aly, S.E. Biological detoxification of mycotoxins: A review. Ann. Microbiol. 2014, 64, 905-919. [CrossRef]

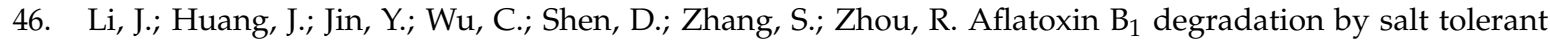
Tetragenococcus halophilus CGMCC 3792. Food Chem. Toxicol. 2018, 121, 430-436. [CrossRef]

47. Li, J.; Huang, J.; Jin, Y.; Wu, C.; Shen, D.; Zhang, S.; Zhou, R. Mechanism and kinetics of degrading aflatoxin $\mathrm{B}_{1}$ by salt tolerant Candida versatilis CGMCC 3790. J. Hazard. Mater. 2018, 359, 382-387. [CrossRef]

48. Wang, Y.; Zhang, H.; Yan, H.; Yin, C.; Liu, Y.; Xu, Q.; Liu, X.; Zhang, Z. Effective biodegradation of aflatoxin $\mathrm{B}_{1}$ using the Bacillus licheniformis (BL010) strain. Toxins 2018, 10, 497. [CrossRef]

49. Wang, L.; Wu, J.; Liu, Z.; Shi, Y.; Liu, J.; Xu, X.; Hao, S.; Mu, P.; Deng, F.; Deng, Y. Aflatoxin B 1 degradation and detoxification by Escherichia coli CG1061 isolated from chicken. Front. Pharmacol. 2019, 9. [CrossRef]

50. Rao, K.R.; Vipin, A.V.; Hariprasad, P.; Appaiah, K.A.A.; Venkateswaran, G. Biological detoxification of aflatoxin $\mathrm{B}_{1}$ by Bacillus licheniformis CFR1. Food Control 2016, 71, 234-241.

51. Alberts, J.F.; Engelbrecht, Y.; Steyn, P.S.; Holzapfel, W.H.; Van Zyl, W.H. Biological degradation of aflatoxin $\mathrm{B}_{1}$ by Rhodococcus erythropolis cultures. Int. J. Food Microbiol. 2006, 109, 121-126. [CrossRef] [PubMed]

52. Pel, H.J.; De Winde, J.H.; Archer, D.B.; Dyer, P.S.; Hofmann, G.; Schaap, P.J.; Turner, G.; De Vries, R.P.; Albang, R.; Albermann, K.; et al. Genome sequencing and analysis of the versatile cell factory Aspergillus niger CBS 513.88. Nat. Biotechnol. 2007, 25, 221-231. [CrossRef] [PubMed]

53. Miyake, Y.; Ito, C.; Itoigawa, M.; Osawa, T. Isolation of the antioxidant pyranonigrin-A from rice mold starters used in the manufacturing process of fermented foods. J. Agric. Chem. Soc. Jpn. 2007, 71, 2515-2521. [CrossRef] [PubMed]

54. Inglis, D.O.; Binkley, J.; Skrzypek, M.S.; Arnaud, M.B.; Cerqueira, G.C.; Shah, P.; Wymore, F.; Wortman, J.R.; Sherlock, G. Comprehensive annotation of secondary metabolite biosynthetic genes and gene clusters of Aspergillus nidulans, A. fumigatus, A. niger and A. oryzae. BMC Microbiol. 2013, 13, 91. [CrossRef] [PubMed]

55. Kurome, T.; Inami, K.; Inoue, T.; Ikai, K.; Takesako, K.; Kato, I.; Shiba, T. Total synthesis of an antifungal cyclic depsipeptide aureobasidin A. Tetrahedron 1996, 52, 4327-4346. [CrossRef]

56. Choi, J.S.; Lee, H.J.; Park, K.Y.; Ha, J.O.; Kang, S.S. In vitro antimutagenic effects of anthraquinone aglycones and naphthopyrone glycosides from Cassia tora. Planta Med. 1997, 63, 11-14. [CrossRef]

57. Walton, J.D. HC-toxin. Phytochemistry 2006, 67, 1406. [CrossRef]

58. Godio, R.P.; Fouces, R.; Gudiña, E.J.; Martín, J.F. Agrobacterium tumefaciens-mediated transformation of the antitumor clavaric acid-producing basidiomycete Hypholoma sublateritium. Curr. Genet. 2004, 46, 287-294. [CrossRef]

59. Yin, C.; Wang, B.; He, P.; Lin, Y.; Pan, L. Genomic analysis of the aconidial and high-performance protein producer, industrially relevant Aspergillus niger $\mathrm{SH}_{2}$ strain. Gene 2014, 541, 107-114. [CrossRef] 
60. Gong, W.; Cheng, Z.; Zhang, H.; Liu, L.; Gao, P.; Wang, L. Draft genome sequence of Aspergillus niger strain An76. Genome Announc. 2016, 4, e01700-15. [CrossRef]

61. Yin, X.; Shin, H.; Li, J.; Du, G.; Liu, L.; Chen, J. Comparative genomics and transcriptome analysis of Aspergillus niger and metabolic engineering for citrate production. Sci. Rep. 2017, 7, 41040. [CrossRef] [PubMed]

62. Malekpour, A.; Bayati, S. Stimultaneous determination of aflatoxins in pistachio using ultrasonically stabilized chloroform/water emulsion and HPLC. Food Anal. Methods 2015, 9, 805-811. [CrossRef]

63. Ames, B.N.; Durston, W.E.; Yamasaki, E.; Lee, F.D. Carcinogens are mutagens: A simple test system combining liver homogenates for activation and bacteria for detection. Proc. Natl. Acad. Sci. USA 1973, 70, 2281-2285. [CrossRef] [PubMed]

Publisher's Note: MDPI stays neutral with regard to jurisdictional claims in published maps and institutional affiliations.

(C) 2020 by the authors. Licensee MDPI, Basel, Switzerland. This article is an open access article distributed under the terms and conditions of the Creative Commons Attribution (CC BY) license (http://creativecommons.org/licenses/by/4.0/). 